\title{
Immune Response to B19 Parvovirus and an Antibody Defect in Persistent Viral Infection
}

Gary J. Kurtzman, * Bernard J. Cohen, ${ }^{\prime}$ Anne M. Field, ${ }^{\ddagger}$ Ronald Oseas, ${ }^{5}$ R. Michael Blaese," and Neal S. Young* ${ }^{*}$ Cell Biology Section, Clinical Hematology Branch, National Heart, Lung, and Blood Institute, Bethesda, Maryland 20892; ${ }^{\ddagger}$ Virus Reference Laboratory, Central Public Health Laboratory, Colindale, London, United Kingdom NW9 5HT; ${ }^{\circledR}$ Department of Pediatrics, Harbor-UCLA Medical Center, Torrance, California 90509; and "Division of Cancer Biology and Diagnosis, National Cancer Institute, Bethesda, Maryland 20892

\begin{abstract}
B19 parvovirus has been shown to persist in some immunocompromised patients, and treatment with specific antibodies can lead to decreased quantities of circulating virus and hematologic improvement. A defective immune response to B19 parvovirus in these patients was shown by comparison of results using a capture RIA and immunoblotting. In normal individuals, examination of paired sera showed that the dominant humoral immune response during early convalescence was to the virus major capsid protein $(58 \mathrm{kD})$ and during late convalescence to the minor capsid species $(83 \mathrm{kD})$. In patients with persistent parvovirus infection, variable titers against intact particles were detected by RIA, but the sera from these patients had minimal or no IgG to capsid proteins determined by Western analysis. Competition experiments suggested that this discrepancy was not explicable on the basis of immune complex formation alone and that these patients may have a qualitative abnormality in antibody binding to virus. In neutralization experiments, in which erythroid colony formation in vitro was used as an assay of parvovirus activity, sera from patients with poor reactivity on immunoblotting were also inadequate in inhibiting viral infectivity. A cellular response to purified B19 parvovirus could not be demonstrated using proliferation assays and PBMC from individuals with serologic evidence of exposure to virus. These results suggest that production of neutralizing antibody to capsid protein plays a major role in limiting parvovirus infection in man.
\end{abstract}

\section{Introduction}

B19 parvovirus infection in man is usually acute $(1,2)$. The only identified target cell for this virus is an erythroid progenitor of the bone marrow $(3,4)$. Infection in normal individuals is manifest as fifth disease, in which the formation of complexes of antibody and virus is associated with a cutaneous eruption and polyarthralgia (5). In normal persons, infection leads to reticulocytopenia with viremia shortly after inocula-

A portion of this work was included in an abstract published in Blood. 1988. 72(Suppl. 1):45a. (Abstr.)

Address reprint requests to Dr. Neal S. Young, Bldg. 10, Room 7C103, National Institutes of Health, Bethesda, MD 20892. Dr. Kurtzman's present address is Division of Hematology, Stanford University School of Medicine, Stanford, CA 94305.

Received for publication 12 December 1988 and in revised form 5 June 1989.

The Journal of Clinical Investigation, Inc.

Volume 84, October 1989, 1114-1123 tion, but the decline in hemoglobin is minimal because of the brief interruption of erythropoiesis (5). In contrast, in individuals with an increased requirement for erythrocytes and heightened marrow erythopoiesis (hemolysis, ineffective erythropoiesis, blood loss, iron deficiency), B19 parvovirus causes transient aplastic crisis, in which the dominant clinical feature is abrupt worsening of anemia (2). In these infected individuals, the period of viremia is short, and the appearance of virus-specific antibody is followed by brisk marrow recovery.

We have identified patients with persistent B19 parvoviremia that has resulted in chronic bone marrow failure. The first reported case was a patient with Nezelof's syndrome (combined immunodeficiency with immunoglobulins); virus was detected in this child's blood for $>18 \mathrm{mo}$ and hemoglobin and neutrophil number were inversely related to viral titer (6). Another patient with a similarly limited clinical immunologic deficit has been studied by us, in whom parvovirus has been persistent for at least 3 and possibly $>10 \mathrm{yr}$, also resulting in chronic severe anemia (7). Persistent B19 parvovirus infection also may be particularly common among children receiving immunosuppressive chemotherapy for cancer, as the peak incidence of B19 parvovirus infection is in children. Several children with acute lymphocytic leukemia in remission and on maintenance chemotherapy have had chronic anemia and repeatedly viremic sera (8). Finally, we have detected virus in the sera of patients with AIDS who presented with the clinical syndrome of pure red cell aplasia (Frickhofen, N., G. Kurtzman, and N. S. Young, unpublished data).

The host immune response to viruses is complex, and some viruses predominantly elicit either a cellular or humoral immune response (9). Even when neutralizing antibodies or a specific cellular response can be demonstrated in vitro, the protective role of the humoral or cellular arms of the immune system is often inferred from clinical studies of susceptibility in immunosuppressed patients or the results of vaccination. The effectiveness of passive immunization with immunoglobulin (hepatitis A, cytomegalovirus) or hyperimmune serum (hepatitis B, varicella) implies a primary role of antibody in protection against some virus infections. To begin to elucidate the immune response to B19 parvovirus infection, we have studied the antibody and cellular responses to infection in acute and chronic disease.

\section{Methods}

Patients. Blood from six patients with persistent B19 parvoviremia was studied (Table I). The first case, T.W. (6) at presentation was a 31/2-yrold boy with combined immunodeficiency with immunoglobulins (Nezelof's syndrome). He became abruptly anemic and granulocytopenic at age $1 \frac{1}{2} \mathrm{yr}$, when his serum for the first time contained virus; he has been intermittently viremic and transfusion-dependent for more 
Table I. Summary of Results of Anti-B19 Parvovirus Antibody Testing

\begin{tabular}{|c|c|c|c|c|c|c|}
\hline Patient & Diagnosis & Date & IgM & IgG & Immunoblot & Virus \\
\hline \multirow[t]{3}{*}{ T.W. } & CID & 21-IV-86 & 19 & 32 & $\mathrm{Neg}$ & + \\
\hline & & 5-IX-86 & 72 & 19 & $\mathrm{Neg}$ & - \\
\hline & & 4-XI-86 & 31 & 20 & $\mathrm{Neg}$ & + \\
\hline \multirow[t]{2}{*}{ E.Fo. } & CID & 7-III-88 & $>100$ & 17 & Pos & + \\
\hline & & $25-V-88$ & $>100$ & 24 & Pos & + \\
\hline \multirow[t]{5}{*}{ L.G. } & ALL & 28-XII-87 & $<1$ & $<1$ & $\mathrm{Neg}$ & + \\
\hline & & 4-II-88 & $>100$ & 28 & Pos & - \\
\hline & & 8-III-88 & 9 & 14 & Pos & - \\
\hline & & $21-\mathrm{III}-88$ & 2 & 5 & Pos & + \\
\hline & & 21-IV-88 & $>100$ & 39 & Pos & - \\
\hline \multirow[t]{4}{*}{ E.Fr. } & ALL & $22-\mathrm{XI}-87$ & $<1$ & $<1$ & $\mathrm{Neg}$ & + \\
\hline & & 4-II-88 & 84 & 8 & $\mathrm{Neg}$ & \pm \\
\hline & & 31-III-88 & 12 & 17 & Pos & + \\
\hline & & $17-V-88$ & 56 & 46 & Pos & - \\
\hline \multirow[t]{2}{*}{ C.L. } & AIDS & $24-X-86$ & $<1$ & $<1$ & $\mathrm{Neg}$ & + \\
\hline & & $14-X-87$ & 39 & 37 & $\mathrm{Neg}$ & - \\
\hline G.F. & AIDS & 22-XII-87 & $<1$ & $<1$ & Neg & + \\
\hline
\end{tabular}

IgG and IgM were determined by capture RIA and results expressed in arbitrary units. Virus was determined by dot-blot analysis. ALL, acute lymphocytic leukemia; CID, congenital immunodeficiency.

than $2 \mathrm{yr}$. He has no other symptoms suggesting a viral infection, and his only other manifestation of underlying immunodeficiency was an episode of culture-negative pneumonia at age $6 \mathrm{mo}$. Another patient, E.Fo. (7), is a 24-yr-old man who has been parvoviremic for at least 3 and possibly $>10 \mathrm{yr}$, when he and his brother simultaneously and abruptly developed pure red cell aplasia requiring erythrocyte transfusion support. This patient has a presumed diagnosis of underlying immunodeficiency; although he has not had opportunistic infections other than B19 parvovirus, detailed evaluation has shown anergy, suboptimal response of PBMC to a test panel of antigens and mitogens, and low serum IgG levels. Two patients, E.Fr. and L.G., developed chronic parvovirus infection in the setting of acute lymphocytic leukemia in remission and on maintenance chemotherapy (8). Finally, two patients with AIDS secondary to HIV infection had concurrent parvovirus infection. C.L., a 24-yr-old male homosexual with antibodies to HIV, presented with pure red cell aplasia (10). With corticosteroid therapy, he developed Pneumocystis carinii pneumonitis. He later showed dramatic hematologic recovery after treatment with high-dose immunoglobulins. Finally, G.F. was a 27 -yr-old male intravenous drug abuser who presented with septic arthritis and severe anemia. His blood showed the presence of parvovirus, antibodies to HIV, and Staphylococcus aureus; he died $5 \mathrm{~d}$ after admission of sepsis.

All infected patients have been characterized as having intermediate levels of parvoviremia by DNA dot blot analysis $\left(10^{5}-10^{10}\right.$ viral genome copies $/ \mu \mathrm{l}$ serum) and in some (T.W., E.Fr., G.F.) viral replication forms have been demonstrated by Southern analysis of bone marrow cells. The bone aspirate smears in all cases showed absence of erythroid precursors and the presence of giant pronormoblasts.

Control blood samples were obtained from patients with acute parvovirus infection, manifested as transient aplastic crisis or fifth disease, and normal laboratory personnel with serologic evidence of past parvovirus infection.

Detection of serum B19 virus and antibody. Viral DNA was detected by extraction of DNA from $10 \mu \mathrm{l}$ of sera (11) and in some cases cells (12) and dot blot hybridization with a ${ }^{32} \mathrm{P}$-nick-translated fulllength B19 probe (pYT103; 13). Serum was analyzed for viral antigen and anti-B19 virus specific IgM and IgG by RIAs (14). Electron microscopy was performed on pellets after ultracentrifugation of $50 \mu \mathrm{l}$ of serum; negative staining was done using $3 \%$ phosphotungstic acid, pH 6.5.

Immunoblot. Virus from the serum of a patient with transient aplastic crisis was separated from other serum components by centrifugation through $40 \%$ sucrose at $\sim 100,000 \mathrm{~g}$ for $6-16 \mathrm{~h}$ (4). Virus was resuspended in PBS and, after heating to $90-100^{\circ} \mathrm{C}$ for $10 \mathrm{~min}$ under reducing conditions, electrophoresed in $8 \%$ SDS-polyacrylamide (15). After electrophoretic transfer to nitrocellulose, individual lanes were incubated with separate sera in a Deca-Probe apparatus (Hoefer Scientific Instruments, San Francisco, CA) for $1 \mathrm{~h}$ at room temperature. IgG was detected by incubation of the filter with ${ }^{125} \mathrm{I}$-Protein $\mathrm{A}$ or ${ }^{125} \mathrm{I}$-goat anti-human IgG (New England Nuclear, Boston, MA) and IgM by incubation with rabbit anti-human IgM (Miles Laboratories, Naperville, IL) followed by ${ }^{125}$ I-goat anti-rabbit IgG (New England Nuclear) by the nonfat dry milk-antifoam-thimerosal (16) method.

Detection of neutralizing antibody. Sera from the patient were tested for their ability to abrogate the cytotoxic effect of B19 virus in erythroid colony formation assays $(3,4)$. Appropriate controls were selected with approximately equivalent quantities of anti-B19 specific IgG and IgM determined by RIA. $75 \mu$ l of heat-inactivated serum or dilutions were incubated with B19-containing serum at $4^{\circ} \mathrm{C}$ overnight and then serum mixes were incubated with fresh bone marrow mononuclear cells for $4 \mathrm{~h}$ at $4^{\circ} \mathrm{C}$. Erythroid colony-forming cell- $(\mathrm{CFU}-\mathrm{E})^{\mathrm{I}}$ derived colony formation was assayed after incubation of cells in semisolid media at $37^{\circ} \mathrm{C}, 5 \% \mathrm{CO}_{2}, 95 \%$ humidity for 7-8 d.

Cell proliferation assay. PBMC from heparinized blood were prepared by Ficoll-Hypaque density gradient sedimentation and washed twice in RPMI 1640 medium with $2 \%$ autologous serum or FCS. Cells were cultured at a concentration of $2-3 \times 10^{6} / \mathrm{ml}$ in $150 \mu l$ total volume in 96-well microtiter plates in RPMI 1640 medium containing either $15 \%$ autologous serum or FCS with supplemental glutamine, penicillin, and streptomycin; cultures remained at $37^{\circ} \mathrm{C}$ and $95 \% \mathrm{CO}_{2}$ until harvested at days 2,4 , or 6 . Test mitogens and antigens included PHA, Con A, PWM, candida, tetanus toxoid, streptolysin O, and dilutions of partially purified B19 parvovirus or empty parvovirus capsids. Virus was purified by passage of serum over a $40 \%$ sucrose cushion at $38,500 \mathrm{rpm} \times 16 \mathrm{~h}$ and suspension of the pellet in $\sim 100 \mu \mathrm{l}$ of PBS; samples from uninfected sera were prepared similarly. Virus content was estimated by dot-blot analysis with a radioactively labeled virusspecific DNA probe. The serum used (Gray) contained only virus and was free of immune complexes as determined by electron microscopy. In addition, a lysate of a genetically engineered cell line that produces empty B19 parvovirus capsids (17) was also used as an antigen in some experiments. Proliferation was determined by counting washed cells after a 4-h incubation with $\left[{ }^{3} \mathrm{H}\right]$ thymidine (New England Nuclear; 20 $\mathrm{Ci} / \mathrm{mmol} \mathrm{sp} \mathrm{act),} 1 \mu \mathrm{Ci} /$ well.

\section{Results}

Normal humoral response to B19 parvovirus infection. B19 parvovirus has two capsid proteins, which are encoded by overlapping transcripts from the right side of the genome (Fig. $1 ; 18,19)$. The major species, termed VP2, is $58 \mathrm{kD}$ and constitutes $\sim 90 \%$ of the capsid protein (18); the minor species (VP1) is $83 \mathrm{kD}$ and includes 227 amino acids at the amino terminus not present in the major capsid protein species. The

1. Abbreviations used in this paper: CFU-E, erythroid colony-forming cells. 


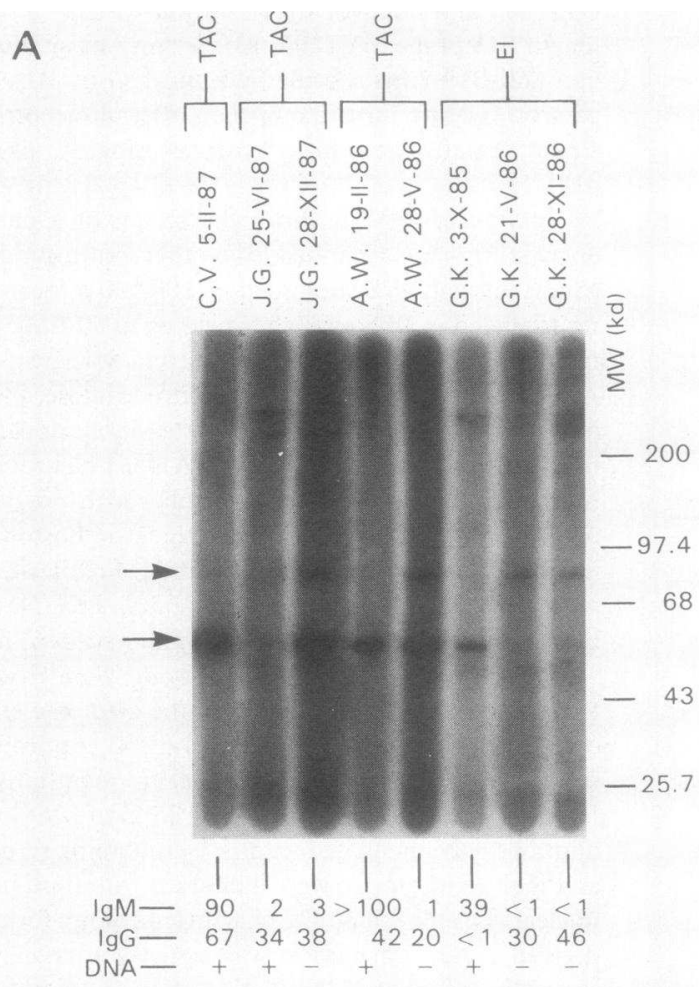

Figure 1. Immunoblot of sera from patients with a history of acute $B 19$ parvovirus infection and nonimmune controls.

Serum containing B19 virus or nonviremic serum was electrophoresed in $8 \%$ SDS-PAGE under denaturing conditions, and after transfer to nitrocellulose each lane was exposed to a different serum sample; all sera were tested at a dilution of 1:50. Antibody binding was detected by autoradiography after incubation with ${ }^{125}$ I-goat anti-human IgG. Arrows, position of the 58and $83-k D$ capsid proteins.

B

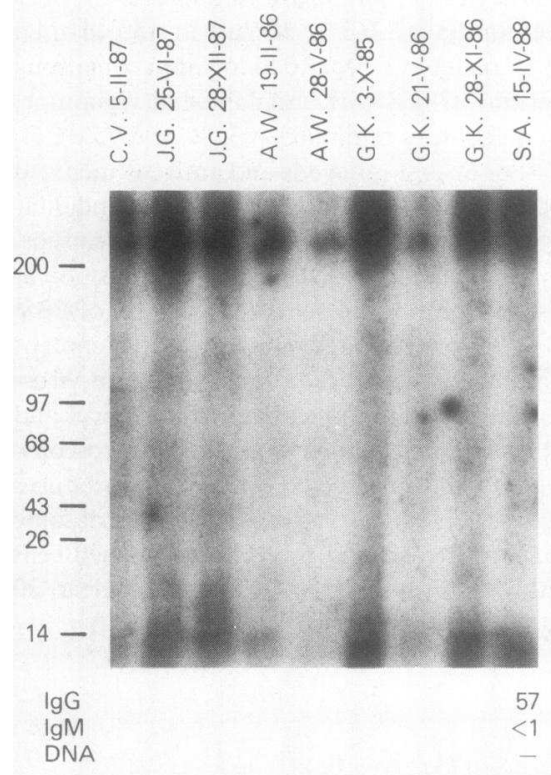

C

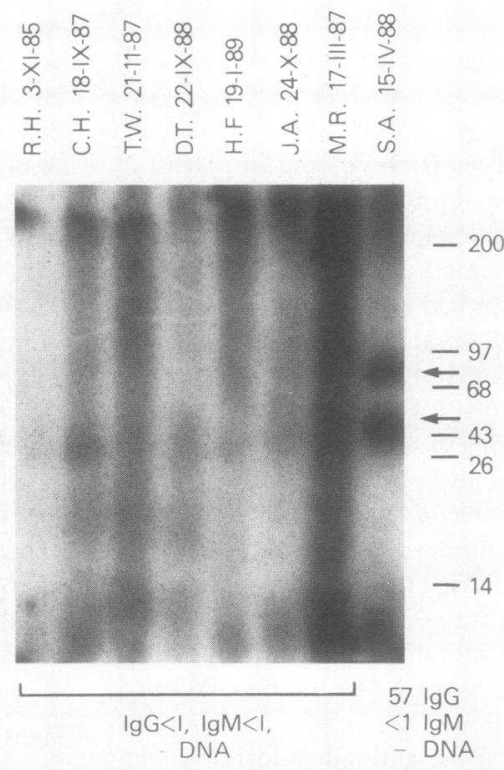

Shown below each lane are titers of virus-specific IgG and IgM determined by capture RIA (expressed in arbitrary units) and the presence $(+)$ or absence $(-)$ of B19 DNA in serum or peripheral blood leucocytes determined by dot blot hybridization for the same blood samples. $(A)$ Immunoblot of sera from patients with acute parvovirus infection with B19 antigen (transient aplastic crisis [TAC] in hemolytic disease, erythema infectiosum [EI] or fifth disease in a normal person). In three cases, paired samples were obtained early, on diagnosis of infection, and during the late convalescent phase; $(B)$ immunoblot of the same sera using nonviremic serum as antigen; $(C)$ immunoblot of nonimmune sera from hematologically normal donors and hematologic controls with a history of frequent transfusions using B19 parvovirus as antigen. Beneath the autoradiograph is a reference diagram of a simplified version of the genomic organization of the B19 parvovirus; note the overlap of the transcripts for the major and minor capsid proteins and the small region unique to the VP1 sequence. 
capsid proteins predicted from analysis of the B19 genomic sequence have been detected using either convalescent human serum after in vitro translation (19) or by rabbit polyclonal serum directed against fusion proteins, which were produced in genetically altered bacteria that carry a portion of the capsid protein gene (20).

We examined 15 sera from patients in whom B19 parvovirus infection had been established by detection of antibodies in a capture radioimmunoassay; on Western analysis, antibody specificities for either the $58-\mathrm{kD}$ capsid protein, the 83-kD capsid protein, or both species were always present. Examination of paired specimens from early and late during the convalescent phase showed a consistent pattern of protein recognition (Fig. $1 \mathrm{~A}$ ). At the time of viremia, IgG antibody to virus was often not detected by immunoblot; however, when it was detected, sera reacted only with the major capsid protein of $58 \mathrm{kD}$. During early convalescence ( $<1 \mathrm{wk}$ from viremia), antibody to the major capsid protein was the predominant or exclusive reactivity. Weeks to months after infection or in sera from an immune population routinely screened, reactivity to the $83-\mathrm{kD}$ protein was present and often dominant. Because

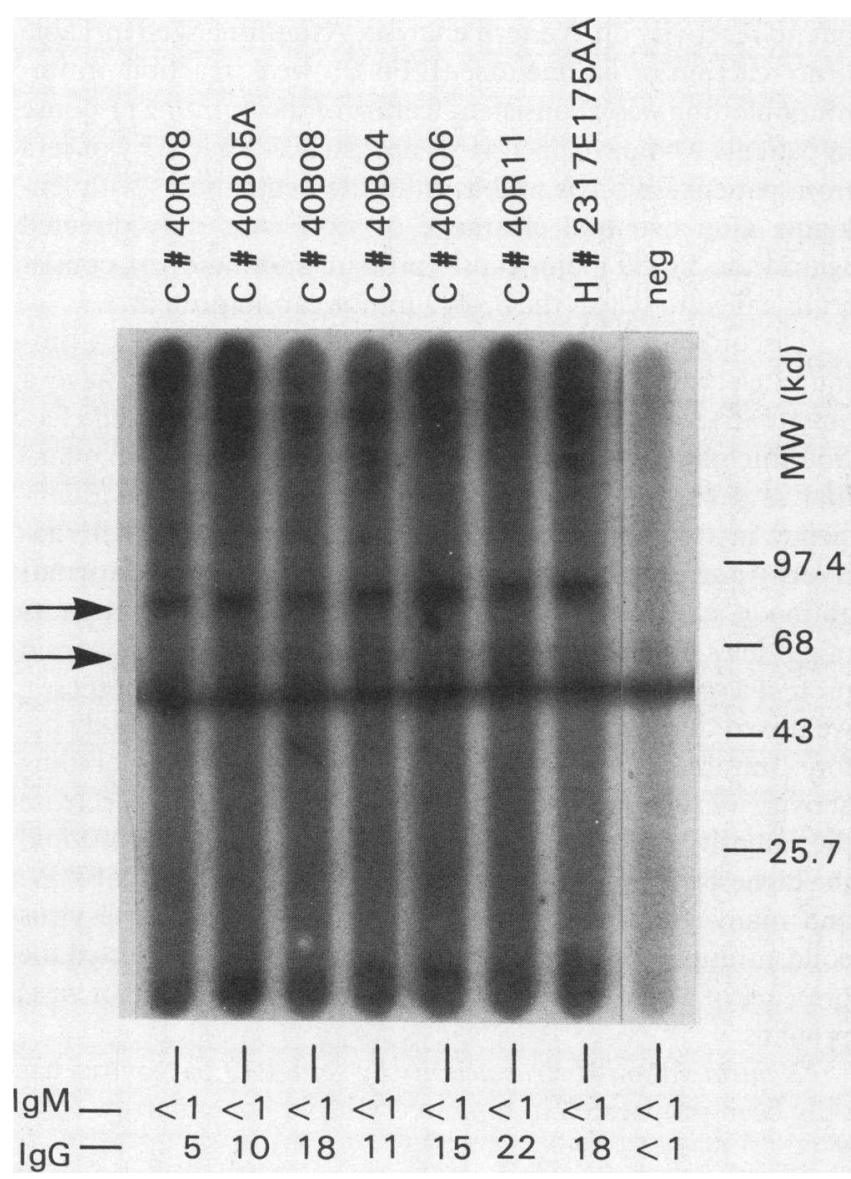

Figure 2. Immunoblot of commercial preparations of immunoglobulin. Six lots of Gammimmune-N (Cutter Biologicals; abbreviated as $C$ with lot number) and one lot of Gammagard (Hyland Laboratories; abbreviated $\mathrm{H}$ with lot number) were assayed at 1:50 dilutions as described in the legend to Fig. 1. Arrows indicate the position of the 58- and 83-kD major and minor capsid proteins. The dense band migrating at $55 \mathrm{kD}$ represents the heavy chain of IgG. No immunoglobulin was added to the lane labeled "neg." much less of the $83-\mathrm{kD}$ protein is present in virus and therefore on the nitrocellulose used for immunoblotting, the Western method probably underestimated the amount of $83-\mathrm{kD}$ specific antibody in serum. In addition, failure to detect a major capsid protein reaction indicated that epitopes present at the amino-terminal end of the $83 \mathrm{kD}$, which are not shared between the two capsid proteins, are specifically recognized. There was no reaction of immune sera to a mock preparation of antigen from a nonviremic individual (Fig. $1 \mathrm{~B}$ ), nor did nonimmune sera from normal individuals or frequently transfused patients with hematologic diseases bind to parvovirus capsid proteins (Fig. 1C).

Commercial immunoglobulin preparations also contained anti-B19 parvovirus antibodies. All of seven lots (six Gammimune, Cutter, Elkhart, IN; one Gammagard, Hyland, Glendale, CA) contained antibodies determined by RIA, and four of four lots showed specificities to both 58- and 83-kD capsid proteins by immunoblot (Fig. 2).

Antibody response to B19 parvovirus in persistent infection. In the first case of persistent infection, both IgM and IgG antibodies specific for $\mathrm{B} 19$ parvovirus were readily detected by

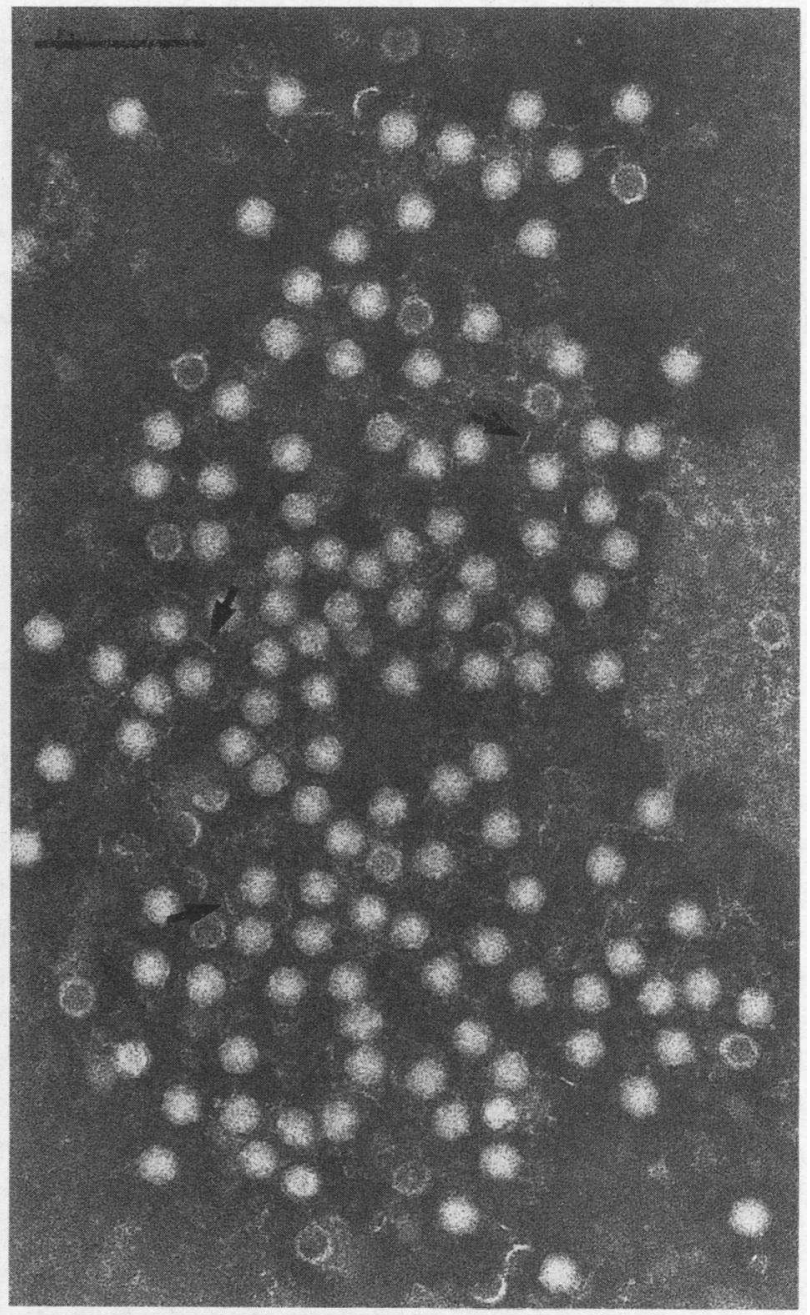

Figure 3. Electron micrograph of parvovirus in patient T.W.'s serum (from 23. ${ }^{\mathrm{VII}} \cdot 86$ ). Viral particles were visible after sedimentation, without added anti-B19 parvovirus serum because of aggregation by patient's antibody, mostly IgM (negative stain, $\times 173,000$, Bar, 100 $\mathrm{nm})$. 

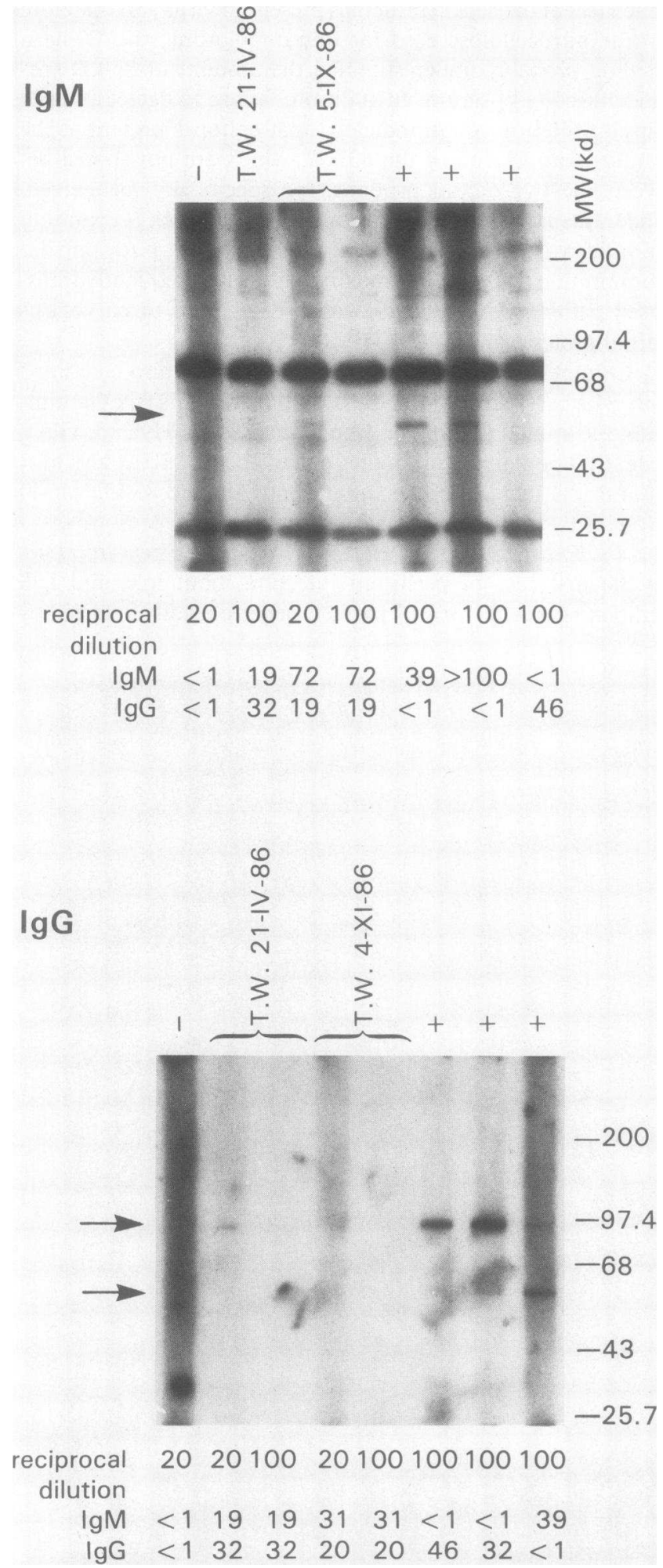

Figure 4. Immunoblot of sera from patient T.W. with congenital immunodeficiency and persistent parvovirus infection. Experiments were performed as described in the legend to Fig. 1, except that antiparvovirus IgM $(A)$ was detected using rabbit anti-human IgM followed by ${ }^{125}$ I-goat antirabbit IgG, and antiparvovirus IgG $(B)$ was detected using ${ }^{125} \mathrm{I}$-protein A. Arrows show the position of capsid protein bands of 83 and $58 \mathrm{kD}$. IgM, which contaminates the virus pellet, is apparent as multiple bands in $A$. The reciprocal of the dilution of serum reacted and the titer of antibody by RIA are shown a capture RIA. In addition, IgM antibodies apparently crosslinking virus particles were visualized by electron microscopy of centrifuged sera from the patient (Fig. 3). However, multiple serum samples failed to react with electrophoresed capsid proteins on immunoblotting for B19 parvovirus-specific IgG and IgM (Fig. 4). (Apparent slight reactivity in one sample only was probably due to recent transfusion with immune plasma from the patient's father.)

To determine whether the absence of anticapsid protein specificity in serum on immunoblot was a consistent feature of persistent infection, we examined sera from other patients with chronic B19 parvoviremia (Fig. 5). Persistent parvovirus infection has been documented in children with acute lymphocytic leukemia in remission receiving immunosuppressive chemotherapy. Sera obtained from these children during periods of viremia and anemia failed to react with capsid proteins on immunoblotting and also had low titers of virus-specific IgG and IgM on RIA, whereas sera from periods in which virus temporarily disappeared from the circulation and at ultimate recovery did react on immunoblot (Table I). In a patient with AIDS who clinically presented with pure red cell aplasia, antibody initially was lacking by both tests. He later recovered erythropoiesis with immunoglobulin therapy (10). A serum sample obtained 1 yr later showed high antibody titers by RIA but no reactivity on Western analysis. As summarized in Table I, no reaction or, in one case (E.Fo.), a weak reaction on immunoblotting was a consistent feature of the immune response in patients who developed virus persistence. Reactivity of sera from patient E.Fo., as well as from the two patients with leukemia after eventual clearance of virus, was only directed against the $58-\mathrm{kD}$ major capsid protein, and these sera consistently failed to detect the $83-\mathrm{kD}$ minor capsid protein.

Discordance between the results of the capture RIA, immune electron microscopy, and immunoblot might have a quantitative or qualitative explanation. As the RIA and electron microscopy also detect immune complexes (14), a quantitative defect in antibody production could result in a deficiency in free antibody for immunoblot detection. Alternatively, patients might produce qualitatively abnormal antibody, capable of binding to conformational determinants of particles in the RIA but not of binding to epitopes of capsid protein as presented on immunoblot. To test these hypotheses, we mixed dilutions of virus with sera containing antibody before immunoblotting. Although some adsorption of binding activity was observed, the amount of virus required to decrease the intensity of the immunoblot reaction was at least 10 -fold the highest concentration of virus present in the blood of T.W. and many more orders of magnitude higher than the virus concentration present in E.Fr. or C.L. This result suggested the presence of a qualitative defect in antibody recognition of virus proteins.

Neutralization of virus activity by sera. B19 parvovirus has only been propagated in human erythroid bone marrow cells.

below the autoradiograph. Patient T.W.'s sera on the dates tested contained parvovirus. Positive control samples $(+)$ from patients with a history of parvovirus infection were selected for equivalent titers of IgG and IgM antibody to parvovirus by RIA. The negative control $(-)$ that lacked B19 parvovirus antibody was from a multiply transfused sickle cell anemia patient. 


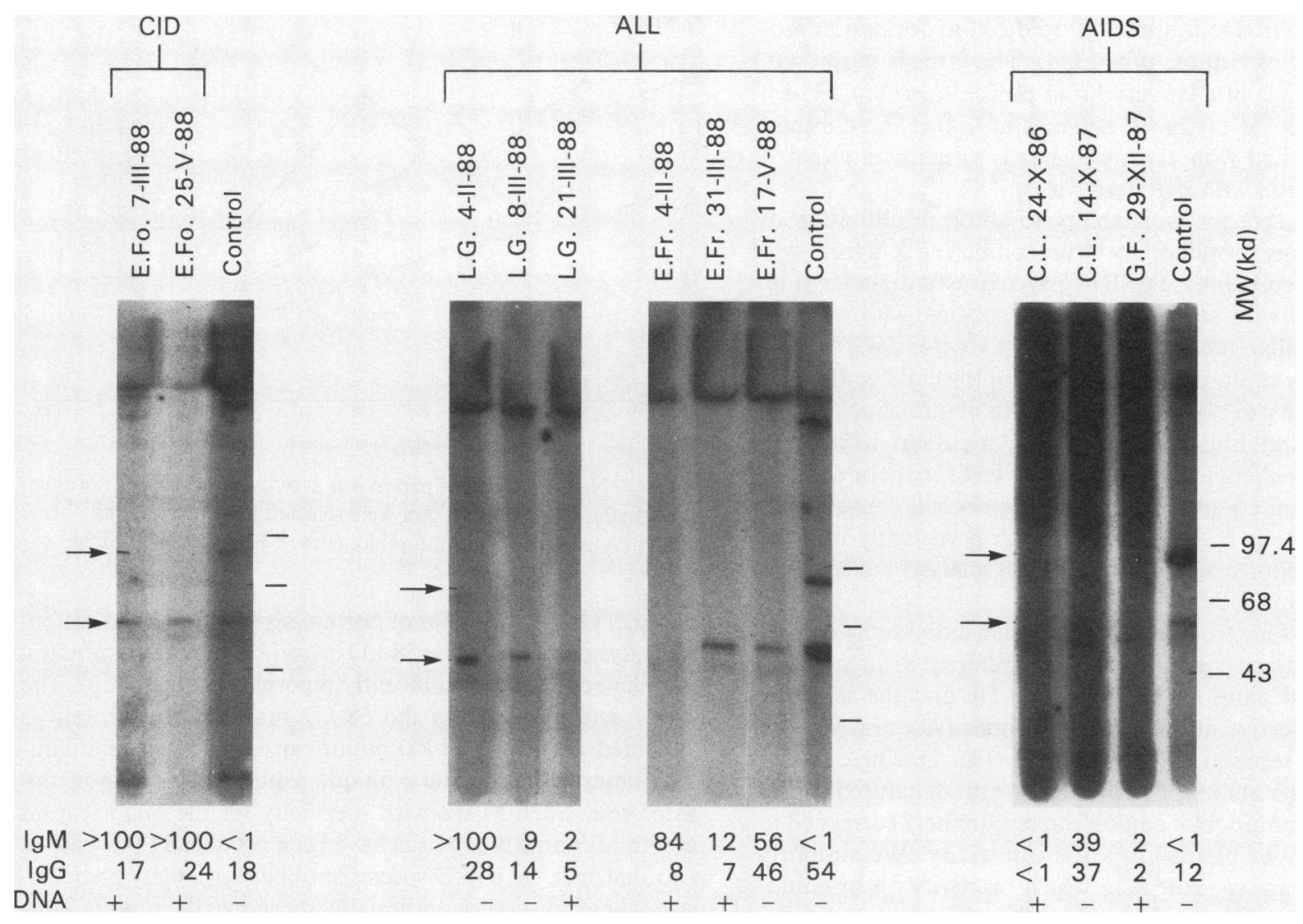

Figure 5. Immunoblot of sera from patients with persistent parvovirus infection. Underlying diagnoses are indicated above the autoradiograph (congenital immunodeficiency [CID], acute lymphocytic leukemia [ALL], AIDS) and the antibody titer by RIA below. The method was as described in the legend to Fig. 1. All patient sera were tested at a dilution of 1:20; the control serum was at 1:50. Arrows show the position of capsid protein bands at 58 and $83 \mathrm{kD}$.

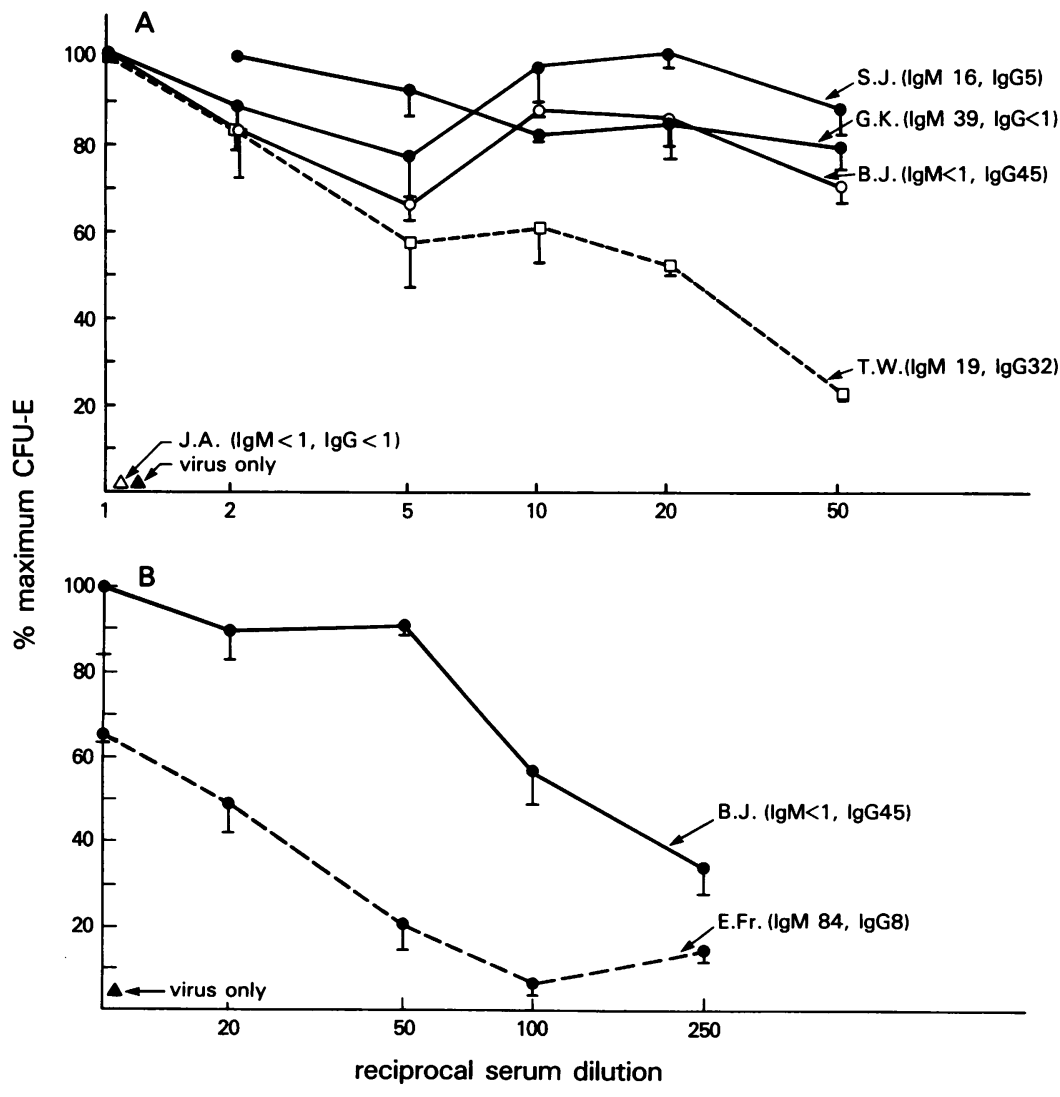

Figure 6. Neutralization of parvovirus activity by sera from persistently infected patients T.W. $(A)$ and E.Fr. $(B)$. Normal sera were selected for equivalent antibody titers by RIA for experiment A. Sera containing antibody to virus were diluted as shown on the abscissa. CFU-E-derived colony formation was almost completely inhibited by the addition of virus alone or by virus mixed with nonimmune serum. Bars represent SEM. 
Ability of the virus to inhibit erythroid colony formation provides an assay of virus activity $(3,4)$. The virus is most cytotoxic at the stage of a late erythroid progenitor cell (CFU-E); the appearance of erythroid colonies at 7-8 $d$ in semisolid medium enriched with erythropoietin is virtually eliminated by preincubation with $\mathrm{B} 19$ parvovirus.

We tested sera for their ability to abrogate inhibition of erythroid colony formation by virus, comparing sera from two patients that contained anti-B19 parvovirus antibodies (Fig. 6). Compared with sera from normal persons, who were selected for similar titers of anti-B19 parvovirus IgG or IgM determined by capture RIA, the serum of the child with Nezelof's syndrome was obviously deficient in neutralizing activity (Fig. $6 \mathrm{~A}$ ). Similarly, the serum from a patient with acute lymphocytic leukemia in remission also had very poor neutralizing activity in comparison to another normal convalescent phase serum (Fig. $6 \mathrm{~B}$ ). Sera from both persistently infected patients had poor reactivity on Western analysis but measurable titers of antibody by capture RIA.

Although sera from normal exposed individuals consistently neutralized virus, there were differences in potency among sera at dilutions higher than 1:50, and the sera that were most effective at blocking virus infectivity also showed the intensest reaction on immunoblot (Fig. 7). These results suggest that the ability of sera to react with denatured capsid proteins on immunoblot could be approximately correlated to their capacity to neutralize virus infectivity. We similarly compared serum specimens in which reactivity on immunoblot was predominantly directed to the major capsid species $(58 \mathrm{kD})$ or to the minor capsid protein $(83 \mathrm{kD})$ (Fig. 8$)$. The equivalent neutralizing ability of these sera indicated that even serum containing antibody restricted to the unique portion of the minor capsid protein, as develops during convalescence, was fully capable of inhibiting infectivity of virus.

Inability to detect a cellular response to B19 parvovirus. Multiple attempts were made to detect a proliferative response by peripheral blood cells to B19 parvovirus. Using preparations of unfractionated blood mononuclear cells from seropositive normal donors, variable concentrations of purified virus, and different times for harvest of cultures, no increase in incorporation of radioactive thymidine was observed (Fig. 9). Because of the possibility that immune complexes formed with antibodies present in autologous serum might block cell access or inhibit proliferation, experiments were performed in which FCS or parvovirus antibody-negative human serum replaced autologus serum, and empty parvovirus capsids generated from a cell line and serum containing virus served as antigens. Under these conditions, we were again unable to detect a proliferative response to virus antigen at 3-7 d (data not shown).

\section{Discussion}

In normal individuals infected, either naturally or experimentally, with B19 parvovirus antibodies to virus form rapidly, usually within a week of inoculation (21). Fifth disease is itself an antibody-mediated, probably immune complex disorder, occurring at the time that antibodies are present in the circulation and seldom associated with the presence of virus in serum (22). (We have observed classic symptoms of fifth disease in immunosuppressed, persistently infected patients following immune plasma [E.Fr.] or immunoglobulin [E.Fo.]

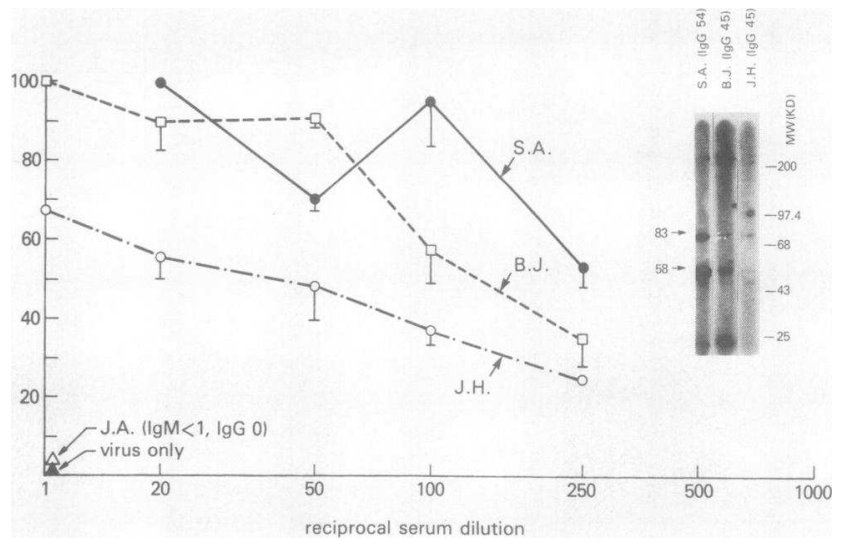

Figure 7. Neutralization of parvovirus activity by sera from normal individuals. Three normal sera were selected based on varying strength of reaction on immunoblot (inset). Bars represent SEM.

therapy.) On immunoblot of normal sera early after infection, antibody specificity to the $58-\mathrm{kD}$ capsid protein predominates; a similar result has been recently reported by others (23). The amino acid sequence of the $58-\mathrm{kD}$ major capsid protein is contained within the $83-\mathrm{kD}$ minor capsid sequence, and antibodies may recognize some unique features of the major capsid protein. Such MAbs with specificity for the major capsid protein of canine parvovirus have been produced (24). Late in convalescence the $83-\mathrm{kD}$ species antibody specificity predominates; these antibodies presumably recognize the unique 227 amino acid region of the larger protein. The topology of the major and minor proteins on the parvovirus capsid surface is not known. The unique region of the $83-\mathrm{kD}$ protein has areas of pronounced hydrophilicity and several predicted alpha helices at the amino terminus, which might contribute to its immunogenicity (25).

Formation of neutralizing antibodies is a consistent feature of acute infection in animals by members of Parvoviridae (26). Diluted sera from patients who have been exposed to the virus

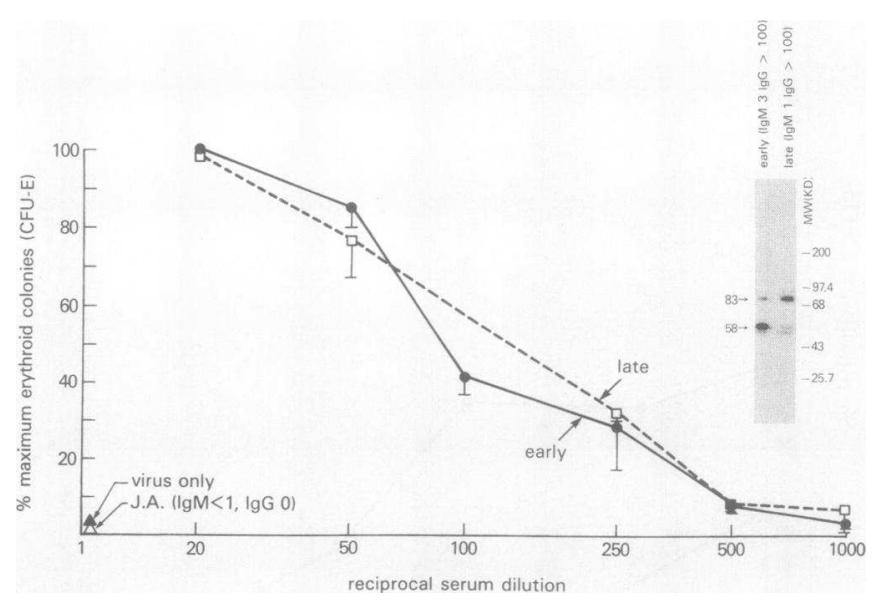

Figure 8. Neutralization of parvovirus activity by normal sera. The ability of sera to block inhibition of erythroid colony formation by virus infection was determined by paired sera from a normal child. Serum obtained in early convalescent phase predominantly bound 58-kD capsid protein, and late convalescent phase serum bound 83-kD protein as shown in the inset immunoblot. Bars represent SEM. 
can partially or entirely neutralize the inhibitory effect of virus on erythropoietic colony formation; sera containing either IgM or IgG have virus neutralizing ability (4). Sera that contain antibodies directed predominantly to the $83-\mathrm{kD}$ minor capsid protein specificities were equivalent to sera containing predominantly anti-58-kD major capsid specificities (experiments with diluted sera indicated that this was not an artifact secondary to underestimation of the amount of antibody to the minor capsid species by the immunoblot technique). In contrast, we were unable to demonstrate a proliferative cellular response to B19 parvovirus, using a number of donors and under a variety of experimental conditions. Lymphocytes from some mink infected with Aleutian disease virus also fail to proliferate in vitro on exposure to virus (27-29). Our results would suggest that the humoral response to B19 parvovirus is most important in resolution of disease, a conclusion reinforced by clinical trials.

Persistent infection with B19 parvovirus in humans causes chronic anemia. Persistence has been observed in the fetus (30) and in three populations of immunosuppressed patients: congenital immunodeficiency, acute lymphocytic leukemia receiving chemotherapy, and AIDS. However, none of the patients that we have studied suffered obviously from other opportunistic infections. In other words, chronic parvovirus was the major clinical consequence of their presumed immune deficit, suggesting that in some patients the immune deficit may be restricted, subtle, and only apparent in retrospect. Parvoviruses can infect lymphocytes (31-33), and a strain of the rodent parvovirus minute virus of mice is specifically lymphotrophic and immunosuppressive (33). Although it is not possible to exclude rigorously an effect of the human parvovirus on the immune response, we have not been able to demonstrate B19 parvovirus replication in lymphocytes cultured in vitro or the presence of the virus in lymphocytes of persistently infected patients (Kurtzman, G. J., and N. S. Young, unpublished data).

Persistent infection of animal parvoviruses in young hosts is common: virus is shed in feces and urine for long periods after initial inoculation, during either convalescence or in latent infection, in mink (34), cats (35), and pigs (36). The rela- tionship of persistent animal parvovirus infection to antibody production is complicated. Formation of neutralizing antibodies is believed to have a major role in resolution of acute infection in adult animals (37), but virus-specific antibodies are often present in persistently infected neonatal animals, and abnormally elevated titers of antibody have been associated with latency. Reappearance of clinical illness in animals has followed immunosuppressive therapy. In Aleutian mink disease, which is chronic and often fatal, tissue damage is the result of deposition of immune complexes of parvovirus antigen and antiviral IgG antibodies that fail to neutralize virus (38).

In our experiments, there was discordance between the results of capture RIA and immunoblot in detection of antiparvovirus antibody. As these patients were viremic, one obvious explanation is that antivirus antibody was present in complex with virus. Such complexes with IgM were visualized by electron microscopy of T.W.'s sera. Antibodies in immune complexes would be predicted to be detected in the capture RIA, as they would bind to plastic coated with anti-human IgG and IgM antibodies, and virus in complexes could be recognized by the antivirus $M A b$. In the absence of free antibody or antigen binding sites, antivirus antibody in complexes would not be detected in immunoblot. However, control experiments showed that failure to react on immunoblot was not a consequence of immune complex formation. A qualitative antibody defect was further suggested by the presence of some activity in neutralization assays, indicating the availability of free antigen bindings sites. These results suggest that some patients (leukemia in remission with chemotherapy) do not produce anti-B19 parvovirus antibody (a quantitative defect) and that other patients (congenital and acquired immunodeficiency) may produce antibodies that fail both to recognize capsid protein epitopes and to neutralize virus activity. An example of a combined quantitative and qualitative defect in antibody production in response to viruses is infection of ferrets with Aleutian disease virus: in animals with low titers of antibody, antibody is directed primarily against conformational virus determinants, whereas ferrets with high titers also produce antibody to sequential determinants detectable on

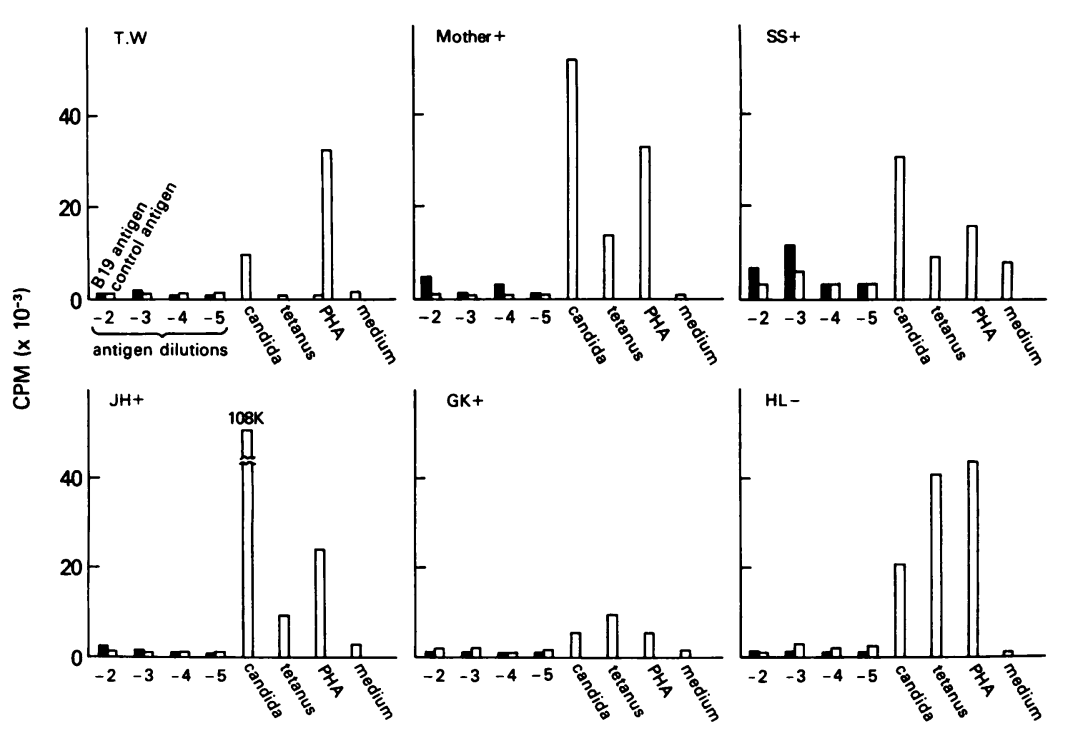

Figure 9. Cellular response to parvovirus. Peripheral blood mononuclear cells from patient T.W. with persistent infection, his mother (with high titers of antiB19 antibodies by RIA), three individuals with serologic evidence of past parvovirus infection (S.S., J.H., and G.K.) and a seronegative person (H.L.) were assayed for proliferation in response to purified B19 parvovirus at varying concentrations $\left(10^{-2}-10^{-5}\right.$ dilutions of a preparation that contained genome $10^{11}$ genome copies/ml; shaded bars), to normal sera processed as for virus purification (open bars), and to test antigens candida, tetanus, and PHA. Cells incubated in medium without antigen or mitogen served as a negative control (medium). In this experiment, cells were incubated for $7 \mathrm{~d}$ with test antigens before addition of $\left[{ }^{3} \mathrm{H}\right]$ thymidine; there was also no reactivity to $B 19$ parvovirus at $3 \mathrm{~d}$. 
Western analysis (39). In general, animals repeatedly exposed to antigen not only switch from IgM to IgG production but also show progressively higher levels of $\mathrm{IgG}$ with increasing affinity and specificity (40). The late production in normal persons of neutralizing IgG that is directed toward more restricted epitopes on the B19 parvovirus minor capsid species may be the result of selection of $B$ cell clones. In patients persistently infected with B19 parvovirus, the prolonged period of elevated antivirus IgM (Table I) as well as the lack of antibody specificity for the $83-\mathrm{kD}$ minor capsid species would also support a class switching defect.

The major immune response to B19 parvovirus appears to be humoral. Based on these data, we have treated several persistently infected patients with immunoglobulin preparations. T.W. received both his father's plasma and commercial immunoglobulin; he experienced a transient reticulocytosis to $8 \%$ and erythroid precursors appeared in the bone marrow, although the hemoglobin did not rise, possibly due to iatrogenic hemolysis from the high concentrations of IgG infused. E.Fr. underwent a course of treatment with his father's plasma and experienced a brief reticulocyte response as well as severe fifth disease; sufficient plasma could not be administered to sustain antiparvovirus immunoglobulin levels. E.Fo. has received very high doses of commercial IgG and has had a complete hematologic remission, associated with disappearance of virus from the circulation (7). Correction of the antibody deficit in persistently infected patients may allow reversal of their hematologic disease.

\section{Acknowledgments}

Dr. J. Antuñez and Dr. J. Donald Temple of the University of Miami (Miami, FL) and Dr. David Mintzer of the Pennsylvania Hospital, (Philadelphia, PA) kindly provided patient samples. Mr. J. Ayub, Mrs. Stacie Anderson, and Miss M. M. Buckley provided expert technical assistance.

\section{References}

1. Anderson, M. J., and J. D. Cherry. 1987. Fifth disease. In Pediatric Infectious Diseases. R. D. Feigin, J. D. Cherry, editors. W. B. Saunders \& Co., Philadelphia. 1646-1653.

2. Young, N. S. 1988. Hematologic and hematopoietic consequences of B19 parvovirus infection. Semin. Hematol. 25:159-172.

3. Mortimer, P. P., R. K. Humphries, J. G. Moore, R. H. Purcell, and N. S. Young. 1983. A human parvovirus-like virus inhibits hematopoietic colony formation in vitro. Nature (Lond.). 302:426-429.

4. Young, N. S., P. P. Mortimer, J. G. Moore, and R. K. Humphries. 1984. Characterization of a virus that causes transient aplastic crisis. J. Clin. Invest. 73:224-230.

5. Anderson, M. J., P. G. Higgins, L. R. Davis, J. S. Willman, S. E. Jones, I. M. Kidd, J. R. Pattison, and D. A. J. Tyrrell. 1985. Experimental parvoviral infection in humans. J. Inf. Dis. 152:257-265.

6. Kurtzman, G., K. Ozawa, B. Cohen, R. Oseas, and N. S. Young. 1987. Chronic bone marrow failure due to persistent B19 parvovirus infection. N. Engl. J. Med. 317:287-294.

7. Kurtzman, G., N. Frickhofen, J. Kimball, D. W. Jenkins, A. W. Nienhuis, and N. S. Young. 1989. Pure red cell aplasia of ten years' duration due to persistent B19 parvovirus infection and its cure with immunoglobulin therapy. $N$. Engl. J. Med. In press.

8. Kurtzman, G., B. Cohen, P. Meyers, A. Amanullah, and N. S. Young. 1988. Persistent B19 parvovirus infection as a cause of severe chronic anemia in children with acute lymphocytic leukemia. Lancet. ii:1159-1162.
9. Sissons, J. G. P., and M. B. A. Oldstone. 1985. Host responses to viral infections. In Virology. B. N. Fields, editor. Raven Press, New York. 265-279.

10. Mintzer, D., and R. Reilly. 1987. Pure red cell aplasia associated with human immunodeficiency virus infection: response to intravenous gammaglobulin. Blood. 70(Suppl. 1):124a. (Abstr.)

11. Clewley, J. P. 1985. Detection of human parvovirus using a molecularly cloned probe. J. Med. Virol. 15:173-181.

12. Kurtzman, G., P. Gascon, M. Caras, B. Cohen, and N. S. Young. 1988. B19 parvovirus replicates in circulating cells of acutely infected patients. Blood. 71:1448-1454.

13. Ozawa, K., G. Kurtzman, and N. S. Young. 1986. Replication of the B19 parvovirus in human bone marrow cultures. Science (Wash. DC). 233:883-886.

14. Cohen, B. J., P. P. Mortimer, and M. S. Pereira. 1983. Diagnostic assays with monoclonal antibodies for the human serum parvovirus-like virus (SPLV). J. Hyg. 91:113-130.

15. Laemmli, U. K. 1970. Cleavage of structural proteins during the assembly of the head of bacteriophage T4. Nature (Lond.). 227:680-684.

16. Johnson, D. A., J. R. Gautsch, J. R. Sportsman, and J. H. Elder. 1984. Improved technique utilizing non-fat dry milk for analysis of proteins and nucleic acids transferred to nitrocellulose. Gene Anal. Tech. 1:3-8.

17. Kajigaya, S., T. Shimada, S. Fujita, and N. S. Young. 1989. A genetically engineered cell line that produces empty capsids of B19 (human) parvovirus. Proc. Natl. Acad. Sci. USA. In press.

18. Ozawa, K., and N. Young. 1987. Characterization of capsid and noncapsid proteins of B19 parvovirus propagated in human erythroid bone marrow cell cultures. J. Virol. 61:2627-2630.

19. Ozawa, K., J. Ayub, and N. S. Young. 1988. Functional mapping of the genome of the B19 (human) parvovirus. J. Virol. 62:25082511 .

20. Cotmore, S. F., V. C. McKie, L. J. Anderson, C. R. Astell, and P. Tattersall. 1986. Identification of the major structural and nonstructural proteins encoded by human parvovirus B19 and mapping of their genes by procaryotic expression of isolated genomic fragments. $J$. Virol. 60:548-557.

21. Saarinen, U. M., T. L. Chorba, P. Tattersall, N. S. Young, L. J. Anderson, and P. Coccia. 1986. Human parvovirus B19-induced epidemic red cell aplasia in patients with hereditary hemolytic anemia. Blood. 67:1411-1417.

22. Chorba, T. L., P. Coccia, R. C. Holman, P. Tattersall, L. J. Anderson, J. Sudman, N. S. Young, E. Curczynski, U. M. Saarinen, R. Moir, D. N. Lawrence, J. M. Jason, and B. Evatt. 1986. The role of parvovirus B19 in aplastic crisis and erythema infectiosum (fifth disease). J. Inf. Dis. 154:383-393.

23. Schwarz, T. F., M. Roggendorf, and F. Deinhardt. 1988. Human parvovirus B19: ELISA and immunoblot assays. J. Virol. Methods. 20:155-168.

24. Surlerauz, M., Bodeus, M., and G. Burtonboy. 1987. Study of canine parvovirus polypeptides by immunoblot analysis. Arch. Virol. 95:271-281.

25. Shade, R. O., M. C. Blundell, S. F. Cotmore, P. Tattersall, and C. R. Astell. 1986. Nucleotide sequence and genome organization of human parvovirus B19 isolated from the serum of a child during aplastic crisis. J. Virol. 58:921-936.

26. Siegl, G. 1984. Biology of pathogenicity of autonomous parvoviruses. In The Parvoviruses. K. I. Berns, editor. Plenum Press, New York. 297-362.

27. An, S. W., and B. N. Wilkie. 1981. Mitogen- and viral antigeninduced transformation of lymphocytes from normal mink and from mink with progressive or nonprogressive Aleutian disease. Infect. Immun. 34:111-114.

28. Race, R. E., M. E. Bloom, and J. E. Coe. 1983. Demonstration of Aleutian disease virus-specific lymphocyte response in mink with 
progressive Aleutian disease: comparison of sapphire and pastel mink infected with different virus strains. J. Immunol. 131:1558-1564.

29. Alexandersen, S., M. E. Bloom, and J. Wolfinbarger. 1988. Evidence of restricted viral replication in adult mink infected with Aleutian disease of mink parvovirus. J. Virol. 62:1495-1507.

30. Anand, A., E. S. Gray, T. Brown, J. P. Clewley, and B. J. Cohen. 1987. Human parvovirus infection in pregnancy and hydrops fetalis. N. Engl. J. Med. 316:183-186.

31. Schultz, R. D., H. Mendel, and F. W. Scott. 1976. Effect of feline panleukopenia virus infection on development of humoral and cellular immunity. Cornell Vet. 66:324-332.

32. Paul, P. S., W. L. Mengeling, and T. T. Brown. 1979. Replication of porcine parvovirus in peripheral blood lymphocytes, monocytes, and peritoneal macrophages. Infect. Immun. 25:1003-1007.

33. Engers, H. D., J. A. Louis, R. H. Zubler, and B. Hirt. 1981. Inhibition of $T$ cell-mediated functions by MVM(i), a parvovirus closely related to minute virus of mice. J. Immunol. 127:2280-2285.

34. An, S. H., and D. G. Ingram. 1977. Detection of inapparent Aleutian disease virus infection in mink. Am. J. Vet. Res. 38:16191624.
35. Csiza, C. K., F. W. Scott, A. de Lahunta, and J. H. Gillespie. 1971. Immune carier state of feline panleukopenia virus-infected cats. Am. J. Vet. Res. 32:419-426.

36. Johnson, R. H., and D. F. Collings. 1971. Transplacental infection of piglets with a porcine parvovirus. Res. Vet. Sci. 12:570-572.

37. Siegl, G. 1988. Patterns of parvovirus infection in animals. In Parvoviruses and Human Disease. J. R. Pattison, editor. CRC Press, Boca Raton, FL. 43-67.

38. Porter, D. D., and H. J. Cho. 1980. Aleutian disease of mink: a model for persistent infection. In Comprehensive Virology, VirusHost Interactions. Viral Invasion, Persistence, and Disease. H. Fraenkel-Conrat and R. R. Wagner, editors. Plenum Press, New York. 16:233-256.

39. Porter, D. D. 1986. Aleutian disease: a persistent parvovirus infection of mink with a maximal but ineffective host immune response. Prog. Med. Virol. 33:42-60.

40. Steiner, L. A., and Eisen, H. N. 1967. Sequential changes in the relative affinity of antibodies synthesized during the immune response. J. Exp. Med. 126:1161-1183. 